\title{
Conditioning of hydrogenated amorphous carbon thin films for field emission via current stressing
}

\author{
J. D. Carey a) and S. R. P. Silva \\ School of Electronics, Computing, and Mathematics, University of Surrey, Guildford, \\ GU2 7XH, United Kingdom
}

(Received 28 August 2000; accepted for publication 20 October 2000)

\begin{abstract}
The effects of electrical current stressing on the field emission characteristics of hydrogenated amorphous carbon $(a-\mathrm{C}: \mathrm{H})$ thin films are reported. In these $a-\mathrm{C}: \mathrm{H}$ films an initial conditioning treatment of the film is often required before the onset of stable emission and only after several voltage cycles do the values of the threshold field tend to converge. By stressing of the film by applying a predetermined current through the film, the initial conditioning treatment can be removed and stable and reproducible emission observed. Retesting of the current stressed films shows that the films remain fully conditioned provided a sufficiently high stress current was initially used. (C) 2001 American Institute of Physics. [DOI: 10.1063/1.1339999]
\end{abstract}

Amorphous carbon $(a-\mathrm{C})$ and its hydrogenated alloy $(a-\mathrm{C}: \mathrm{H})$ have been shown to emit electrons at relatively low electric fields and thus have potential applications as cold cathode materials. ${ }^{1,2} a$-C:H films deposited by rf plasma enhanced chemical vapor deposition (PECVD) also have the advantage of being able to be produced over large areas at low temperatures and often exhibit rms roughnesses of less than $1 \mathrm{~nm}$. However, in these "mirror smooth" films it has often been noted that a conditioning or initiation of the film is required before the onset of reproducible field emission (FE) ${ }^{3,4}$ This often involves the cycling of the voltage upward and downward over 1-2 cycles and is sometimes accompanied by surface damage due to microarcing. ${ }^{3}$ Similar conditioning treatments have also been reported necessary in tetrahedral amorphous carbon $(\mathrm{ta}-\mathrm{C})^{5,6}$ and in diamond films grown by chemical vapor deposition. ${ }^{7}$ The exact nature of this conditioning step and the role of the damage-induced surface microprotrusions is not fully understood, though conditioning may involve an increase in the concentration of threefold coordinated carbon atoms. ${ }^{8}$ For a practical $a-\mathrm{C}(: \mathrm{H})$ based display the values of the threshold field $\left(E_{\mathrm{th}}\right)$ should be as reproducible as possible. Furthermore, to limit the spread in the drive voltages, the hysteresis in the $I-V$ characteristics should be kept to a minimum. In this letter we report on the results of current stressing treatments on $a-\mathrm{C}: \mathrm{H}$ films. By varying the stressing current not only can the need for the initial conditioning treatment be removed but the width of the hysteresis present in the $I-V$ characteristic kept to a minimum.

Films were deposited on the water-cooled earthed electrode of a capacitively coupled rf PECVD system onto $n$-type $1-2 \Omega \mathrm{cm} \mathrm{Si}$ substrates. Feed gases of $\mathrm{CH}_{4}(30 \mathrm{sccm})$ and $\mathrm{He}(75 \mathrm{sccm})$ were used. The deposition pressure was 200 mTorr and a rf power of $200 \mathrm{~W}$ was used which resulted in negative dc self bias of about $10 \mathrm{~V}$. These films are polymeric in nature with a $\mathrm{H}$ content of up to $50 \%$ and a low paramagnetic spin density of about $3 \times 10^{17} \mathrm{~cm}^{-3} \cdot{ }^{10}$ The film thickness was measured using ellipsometry.

${ }^{a)}$ Electronic mail: David.Carey@surrey.ac.uk
The FE characteristics of the films were examined using a sphere-to-plane geometry with a $5 \mathrm{~mm}$ stainless steel ball bearing suspended $30 \mu \mathrm{m}$ above the film with a high positive potential applied in a vacuum better than $4 \times 10^{-6}$ mbar. Although a spherical anode is used it is assumed that the electric field between the anode and the surface of the film can be modeled as a parallel plate. The high voltage is stepped up and down four times and the macroscopic electric field is defined as the applied voltage divided by the vacuum separation; $E_{\text {th }}$ is defined as the macroscopic electric field which gives an emission current of $1 \mathrm{nA}$. It should be noted that in improperly conditioned films there may be significant differences in values of $E_{\text {th }}$ depending on whether the current is read on the upward voltage cycle or on the downward cycle. As a measure of this "hysteresis effect" the difference in the applied fields between the upward and downward voltage cycles at a current of $1 \mathrm{nA}$ is used. Current stressing of the films was performed by contacting the anode to the film and passing a current through the film up to a predetermined level. Each film was tested before stressing by applying a field of up to $100 \mathrm{~V} / \mu \mathrm{m}$ and only those samples which did not emit after this preliminary test were subject to current stressing. Atomic force microscopy (AFM) imaging was carried out using a Digital Instruments Nanoscope IIIa system. Atomic force micrographs, not presented here, show that the rms surface roughness of the as-deposited films to be less than $0.4 \mathrm{~nm}$ on a $5 \mu \mathrm{m}$ square scan area.

For the current stressing measurements several identical films from the same deposition run were examined. In order to minimize any possible dependence on the film thickness, ${ }^{11}$ the same film thickness, in this case $57 \mathrm{~nm}$, was used. For reference the typical value of $E_{\text {th }}$ for films which did emit after conventional conditioning is about $30 \mathrm{~V} / \mu \mathrm{m}$. The three current stress levels chosen were $10^{-8}, 5.2 \times 10^{-8}$, and $2 \times 10^{-7}$ A. The FE characteristics of the film stressed to $10^{-8} \mathrm{~A}$ (not shown) exhibited emission but with an $E_{\mathrm{th}}$ of over $85 \mathrm{~V} / \mu \mathrm{m}$ and a width of the first cycle hysteresis loop of over $20 \mathrm{~V} / \mu \mathrm{m}$. Stressing to a higher current of 5.2 $\times 10^{-8}$ A results in an initial emission at a field of $48 \mathrm{~V} / \mu \mathrm{m}$ though a hysteresis width of $20 \mathrm{~V} / \mu \mathrm{m}$, as shown in Fig. 1. 


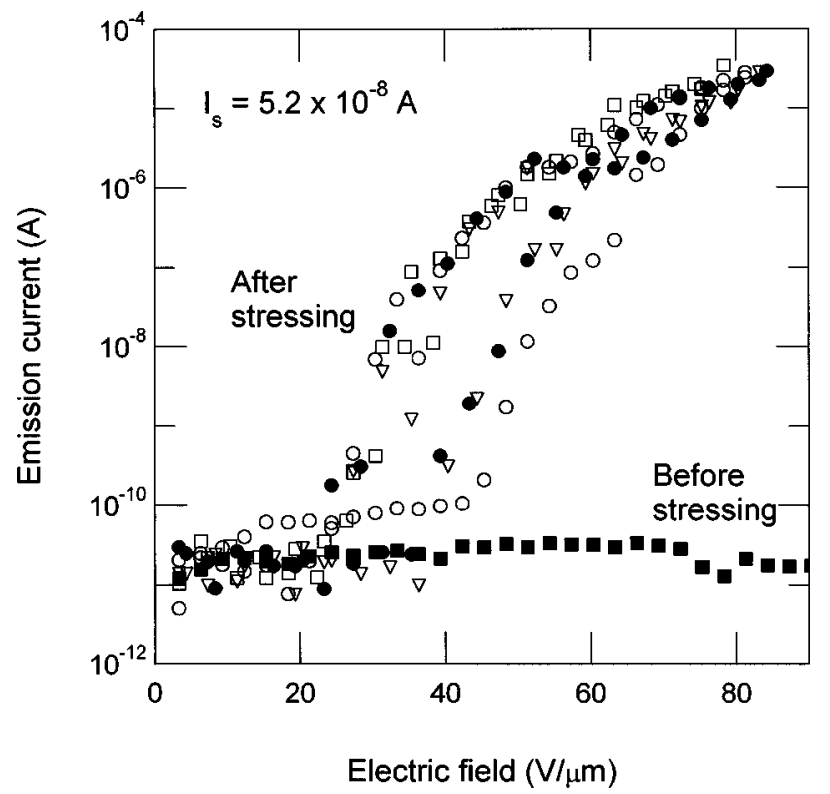

FIG. 1. Emission current vs electric field for films stressed to $5 \times 10^{-8} \mathrm{~A}$. The applied field is cycled up and down four times as indicated by $(\bigcirc)$ for run $1,(\square)$ for run $2,(\bullet)$ for run 3 , and $(\nabla)$ for run 4 . The emission current for the film before stressing is indicted by $(\boldsymbol{\square})$. Not all data points are shown for clarity.

The $I-V$ characteristics of the film before stressing are also presented and show that no emission had occurred from this film even up to fields of $90 \mathrm{~V} / \mu \mathrm{m} . E_{\text {th }}$ continues to decrease after subsequent voltage cycles and finally reached $40 \mathrm{~V} / \mu \mathrm{m}$ after the fourth cycle. The average value of $E_{\text {th }}$ obtained from this film is $38 \pm 10 \mathrm{~V} / \mu \mathrm{m}$, higher than that obtained from a film which underwent the conventional conditioning treatment. It is evident from Fig. 1 that since the width of the first cycle is $20 \mathrm{~V} / \mu \mathrm{m}$ the film is not fully conditioned.

The $I-V$ characteristic of the film stressed to $2 \times 10^{-7} \mathrm{~A}$ is shown in Fig. 2 on the same scale as used in Fig. 1. In this

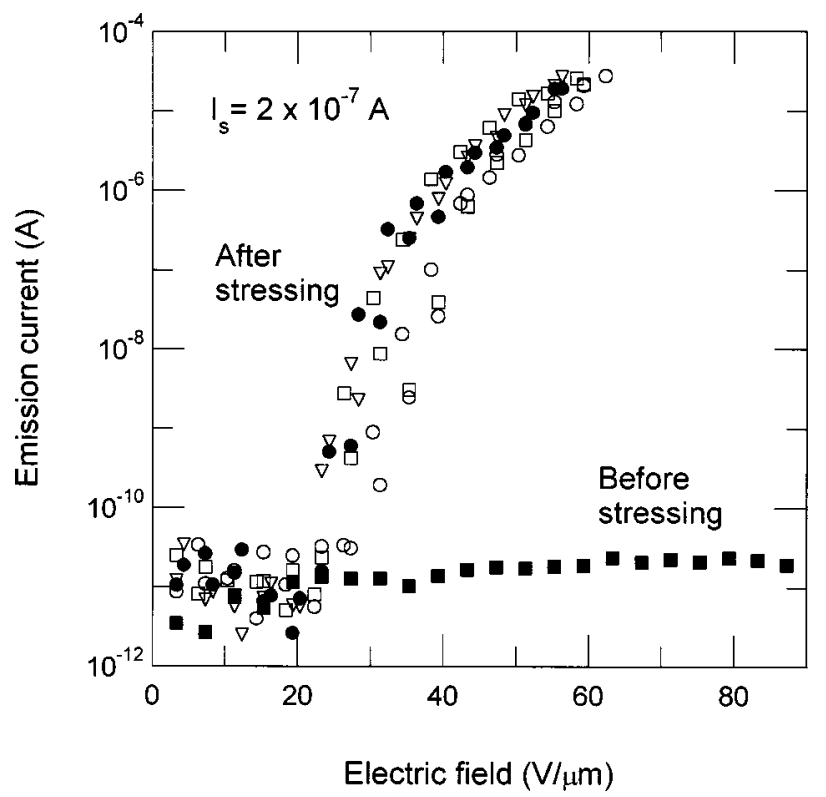

FIG. 2. Emission current vs electric field for films stressed to $2 \times 10^{-7} \mathrm{~A}$. The applied field is cycled up and down four times as indicated by $(\bigcirc)$ for run $1,(\square)$ for run $2,(\bullet)$ for run 3 , and $(\nabla)$ for run 4 . The emission current for the film before stressing is indicted by $(\boldsymbol{\square})$. Not all data points are shown for clarity. (a)

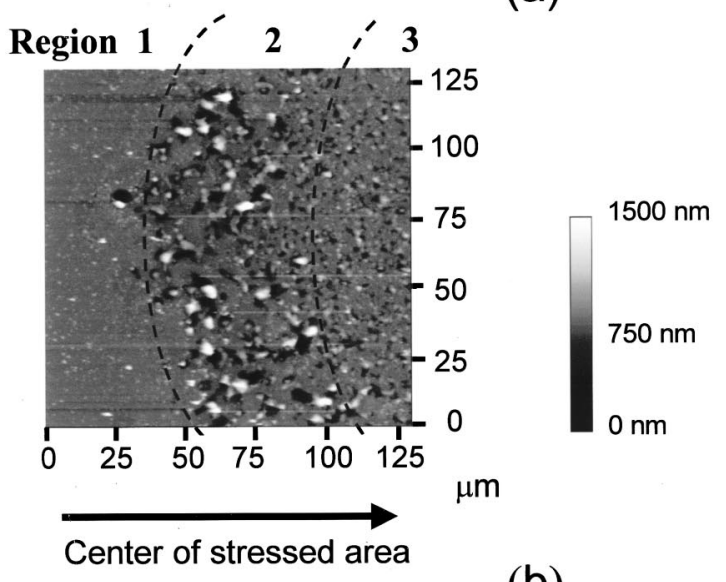

(b)

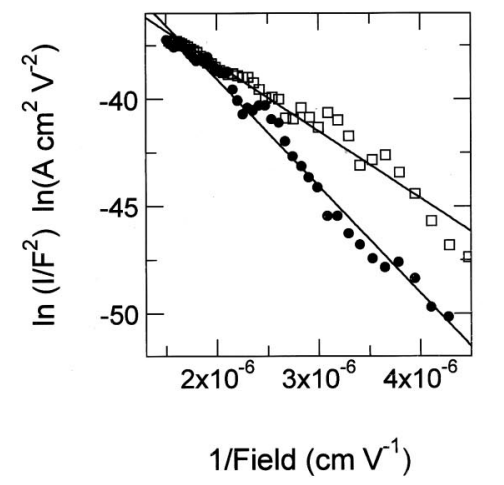

FIG. 3. (a) AFM topography of the surface of the film stressed to 2 $\times 10^{-7} \mathrm{~A}$ area three regions indicated by dashed lines. The center of stressed area is in region 3. (b) Fowler-Nordheim representation of the $I-V$ characteristics of the film stressed to $2 \times 10^{-7} \mathrm{~A}(\mathbf{)})$ and one of the characteristics of a conditioned but unstressed film ( $\square$ ).

case the value of $E_{\mathrm{th}}$ for the first cycle was only $34 \mathrm{~V} / \mu \mathrm{m}$, which subsequently decreased to 30,26 , and $27 \mathrm{~V} / \mu \mathrm{m}$ in the remaining three cycles. The average $E_{\text {th }}$ of $28 \pm 2 \mathrm{~V} / \mu \mathrm{m}$ is comparable to the values of $E_{\text {th }}$ for films which have undergone an conventional conditioning treatment. The width of the $I-V$ hysteresis loop was about $2 \mathrm{~V} / \mu \mathrm{m}$ in each run and Fig. 2 shows no evidence of a conditioning cycle after current stressing. Since the FE characteristics are different and are observed to improve with higher stress currents, we can eliminate the mechanical effects of contacting between the anode and film as the primary reason for the improvements.

An AFM image of the edge of the stressed area of film stressed to $2 \times 10^{-7} \mathrm{~A}$ is shown in Fig. 3(a) where three distinct regions, labeled 1, 2, and 3 , have been identified. Region 1 consists of surface protrusions the majority of which are less than $80 \mathrm{~nm}$ in height and the film possesses a rms roughness of about $44 \mathrm{~nm}$. The surface protrusions of region 3 are less than $120 \mathrm{~nm}$ in height and the rms roughness is $105 \mathrm{~nm}$. By contrast the protrusions of region 2 are over $800 \mathrm{~nm}$ in height and the roughness is $170 \mathrm{~nm}$. To examine whether the protrusions are the source of the emitted electrons we have used the simplified Fowler-Nordheim equation to relate the emission current $I$ to the local field $\beta F$ via

$$
I=\frac{a A \beta^{2} F^{2}}{\phi} \exp \left(\frac{-b \phi^{3 / 2}}{\beta F}\right),
$$




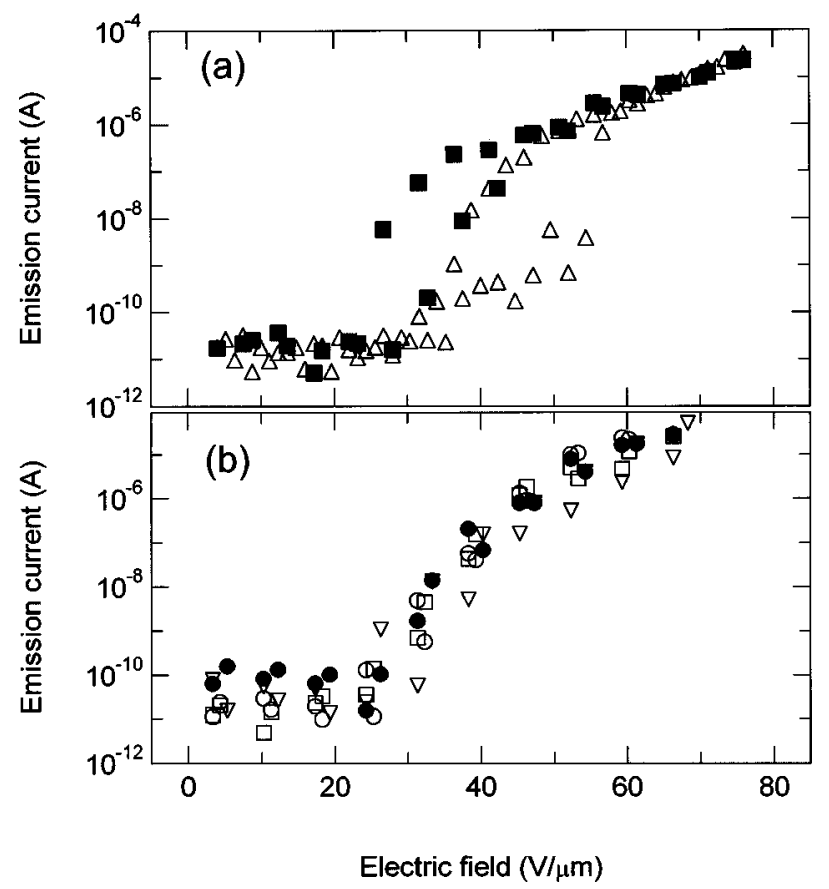

FIG. 4. Emission current vs electric field for films (a) stressed to $5 \times 10^{-8} \mathrm{~A}$ and retested after $15 \mathrm{~h}(\triangle$ and $\boldsymbol{\square})$ and (b) stressed to $2 \times 10^{-7} \mathrm{~A}$ and retested after $23(\bigcirc$ and $\square)$ and $87 \mathrm{~h}(\bullet$ and $\nabla)$. Only the first two cycles of each retest are shown for clarity.

where $a=1.54 \times 10^{-6} \mathrm{AeV} \mathrm{V}^{-2}, \quad b=6.83 \times 10^{7} \mathrm{eV}^{-3 / 2} \mathrm{~V}$ $\mathrm{cm}^{-1}, A$ is the emission area, $\phi$ is the front surface barrier height (in electron volts) and $\beta$ is the field enhancement factor for a field $F$. Figure 3(b) shows the best fits using Eq. (1) to one of the $I-V$ characteristics of the film stressed to $2 \times 10^{-7} \mathrm{~A}$ and one of the characteristics of an unstressed but conditioned film. The slopes of the two lines are -4.98 $\times 10^{6}$ and $-3.2 \times 10^{6}$, which for barriers of $4 \mathrm{eV}$ result in values of $\beta$ of 110 and 170 , respectively. Since the value of $\beta$ from the stressed film is less than that from the unstressed film and the values of the $E_{\mathrm{th}}$ are similar, we believe that the surface protrusions do not play a significant role in the emission process. Values of $\beta \sim 250$, attributed to surface protrusions, were reported in the study by Talin et al. of FE from ta-C and were proposed as the source of the emission. ${ }^{5}$

In order to examine whether the current induced conditioning is permanent the films were retested some hours after the initial stressing had been performed. In order to prevent any possible atmospheric contamination the samples remained held under vacuum during this period. Figure 4(a) shows that even after just $15 \mathrm{~h}$ in the sample that was stressed to $5.2 \times 10^{-8} \mathrm{~A}, E_{\mathrm{th}}$ had risen to about $50 \mathrm{~V} / \mu \mathrm{m}$, similar to the value obtained in the first cycle after this sample had just been stressed, indicating some form of "healing" process had occurred. By contrast Fig. 4(b) shows that in the film stressed to $2 \times 10^{-7}$ A shows no evidence of a conditioning cycle is required $23 \mathrm{~h}$ after the original current stressing had occurred. The values of $E_{\text {th }}$ obtained after $23 \mathrm{~h}$ are 30 and $32 \mathrm{~V} / \mu \mathrm{m}$ with a hysteresis width of $2-3$ $\mathrm{V} / \mu \mathrm{m}$. Testing after $87 \mathrm{~h}$ revealed similar results to those obtained after testing after $23 \mathrm{~h}$ with the values of $E_{\text {th }}$ for the first two cycles being 31 and $32 \mathrm{~V} / \mu \mathrm{m}$, again showing that the film has remained conditioned.

Clearly conditioning of the film through current stressing results in favorable FE characteristics, though it also results in the presence of surface debris. It is also worth pointing out that the lowest values of $E_{\text {th }}$ obtained from the stressed films are almost the same as those obtained from those films which underwent a conventional conditioning treatment. In the study by Mercer $e a^{~}{ }^{8}{ }^{8}$ a scanning tunneling microscope tip was used to effectively current stress $t a$-C films by generating a highly spatially localized electric field. They observed that after ramping the tip-sample bias and current, nanostructures of about $100 \mathrm{~nm}$ in extent form. By using high resolution spatially resolved electron energy loss spectroscopy they showed that the predominant bonding configuration changes from predominately four-fold coordinated $\mathrm{C}$ to three-fold coordinated. The net effect of the conditioning or the current stressing treatments may well be to generate conductive $s p^{2}$ rich areas either in the from of filaments or clusters through localized Joule heating. Missert et al. proposed that the presence of conductive filaments is related to the deposition conditions under which the film was grown. ${ }^{12}$ Since the deposition conditions for the films in this study were kept the same the current stressing may well be increasing the number of such filaments/clusters extending though the film.

In conclusion by current stressing of $a-\mathrm{C}: \mathrm{H}$ films it has been demonstrated that the initial conditioning treatment often required in the FE characteristics from various types of $a-\mathrm{C}: \mathrm{H}$ films can be removed but at the expense of creating surface protrusions. For sufficient current stress levels the film remains conditioned for periods of at least $87 \mathrm{~h}$.

This work has been sponsored by the EPSRC No. GR/ L77638. The authors would like to acknowledge the helpful discussions with Professor J. M. Shannon from Philips Research Laboratories, Redhill.

${ }^{1}$ See, for example, Proceedings of the First International Specialist Meeting on Amorphous Carbon, edited by S. R. P. Silva, J. Robertson, W. I. Milne, and G. A. J. Amaratunga (World Scientific, Singapore, 1998).

${ }^{2}$ J. E. Jaskie, MRS Bull. 21, 59 (1996).

${ }^{3}$ P. W. May, S. Hohn, W. N. Wang, and N. A. Fox, Appl. Phys. Lett. 72, 2182 (1998).

${ }^{4}$ J. D. Carey, C. H. Poa, R. D. Forrest, A. P. Burden, and S. R. P. Silva, J. Vac. Sci. Technol. B 18, 1051 (2000).

${ }^{5}$ A. A. Talin, T. E. Felter, T. A. Friedmann, J. P. Sullivan, and M. P. Siegal, J. Vac. Sci. Technol. A 14, 1719 (1996).

${ }^{6}$ A. Ilie, A. C. Ferrari, T. Yagi, and J. Robertson, Appl. Phys. Lett. 76, 2627 (2000).

${ }^{7}$ A. T. Sowers, B. L. Ward, S. L. English, and R. J. Nemanich, J. Appl. Phys. 86, 3973 (1999).

${ }^{8}$ T. W. Mercer, N. J. DiNardo, J. B. Rothman, M. P. Siegal, T. A. Friedmann, and L. J. Martinez Miranda, Appl. Phys. Lett. 72, 2244 (1998).

${ }^{9}$ N. P. Barradas, R. U. A. Khan, J. V. Anguita, S. R. P. Silva, U. Kreissig, R. Grötzschel, and W. Möller, Nucl. Instrum. Methods Phys. Res. B 161163, 969 (2000).

${ }^{10}$ M. Collins, R. C. Barklie, J. V. Anguita, J. D. Carey, and S. R. P. Silva, Diamond Relat. Mater. 9, 781 (2000).

${ }^{11}$ R. D. Forrest, A. P. Burden, S. R. P. Silva, L. K. Cheah, and X. Shi, Appl. Phys. Lett. 73, 3784 (1998)

${ }^{12}$ N. Missert, T. A. Friedmann, J. P. Sullivan, and R. G. Copeland, Appl. Phys. Lett. 70, 1995 (1997) 